\title{
Article \\ Enhancing Healthcare Project Definition with Lean-Led Design
}

\author{
Hafsa Chbaly * (D) and Maude Brunet \\ Department of Management, HEC Montréal, Montreal, QC H3T 2A7, Canada; maude.brunet@hec.ca \\ * Correspondence: hafsa.chbaly@hec.ca
}

\begin{abstract}
Decisions regarding project definition have a significant impact on client value generation. However, although this phase is of utmost importance, traditional management practices are inadequate, as the focus is rather on budget and technical aspects leaving aside the functional ones. Neglecting the functional aspects could have serious consequences on the operation and thus quality of workspace, especially in complex projects including hospitals that involve multiple clients and with a high degree of uncertainty of change. The Lean-led Design approach provides a participative solution which involves the main project clients, namely the users (doctors, patients, etc.), project managers, and the government, with the intention of delivering facilities with a better fit for purpose and use. The main objective of the paper is to develop a framework that summarizes the steps leading to the implementation of such an approach during the project definition of a new hospital. The methodology chosen is a case study and the main contribution is to develop theoretical knowledge regarding its implementation. This may support managers in their decisions when coordinating project definitions.
\end{abstract}

Keywords: Lean; healthcare design; project definition; design; participative approach; user involvement; requirement; alignment

check for

updates

Citation: Chbaly, H.; Brunet, M. Enhancing Healthcare Project Definition with Lean-Led Design. Sustainability 2022, 14, 1588.

https://doi.org/10.3390/su14031588

Academic Editor: José Carmelo

Adsuar Sala

Received: 23 December 2021

Accepted: 27 January 2022

Published: 29 January 2022

Publisher's Note: MDPI stays neutral with regard to jurisdictional claims in published maps and institutional affiliations.

Copyright: (c) 2022 by the authors. Licensee MDPI, Basel, Switzerland. This article is an open access article distributed under the terms and conditions of the Creative Commons Attribution (CC BY) license (https:// creativecommons.org/licenses/by/ $4.0 /)$.

\section{Introduction}

Many researchers have emphasized the importance of effectively managing and understanding project definition more comprehensively [1-3]. This phase is the first of a project life cycle in which value generation is mainly done [4,5]. It refers to three stages: (1) planning, (2) programming, and (3) schematic design [6,7], whereby client needs are defined and design solutions are proposed.

However, the identification of client needs becomes increasingly complex, especially for healthcare projects $[8,9]$. In these projects, different clients are involved, whether that be funders, managers, or users. Every client has his/her own needs that might be in contradiction with other stakeholder interests $[10,11]$. Moreover, hospitals contain a large number of elements, such as hospital departments that dynamically interact or equipment [11]. In addition, the needs that should be identified during the project definition stage tend to evolve over time [12]. There is constant progress in technologies, so new treatments will be available which require the workspace to be adapted accordingly [9].

Furthermore, a poorly designed healthcare setting could have a negative impact on patient health, such as hospital-acquired infections [13]. In fact, these infections represent the first reason for patient death in the United States [14,15]. In addition, patient satisfaction regarding their emotional desires and social needs is an eminent component of any type of medical service provision [16].

However, due to the traditional briefing practices, the majority of healthcare workspaces are inappropriate in many different aspects [17]. The traditional approach toward workspace design so far seems inefficient in hospital projects [4]. This results in an alignment gap between client needs and design solutions [18].

Lean-led Design as a participative approach is proposed to find the right balance between client needs and design solutions [19]. It represents an approach in which design 
teams work closely with staff to understand the role the environment plays in implementing programmatic and functional space requirements. The Lean-led Design approach has grown in popularity, especially in the UK and US for delivering hospital buildings that offer a greater quality of care services and/or hospital processes. Among various other benefits, this approach helped to save time and reduce the distance walked by nurses by $71 \%[11,20]$.

Up until now, few researchers have conducted investigations specifically designed to target the knowledge of dynamic processes and client inclusion in the project definition stage [21]. Moreover, literature using the Lean-led Design approach remains poor in terms of its implementation methods. Papers published about using this approach are little [3].

That is why an explorative case study of a Canadian mega-hospital, in which Leanled Design has been used, was performed. The research questions for this research are as follows: (1) How was Lean-led Design implemented? (2) How did Lean-led Design contribute to the project definition of a new hospital?

Uncovering and analysing the different steps followed by the hospital to implement a Lean approach during project definition, this paper aims to develop theoretical knowledge regarding its implementation. This paper is organized as follows: Section 2 aims at presenting the conventional practices when managing clients' needs in healthcare projects. Section 3 presents the Lean approach in the healthcare sector. Section 4 presents the methodology used to achieve our objectives and the case study chosen. In Section 5, the results are presented. In the final sections, the results are discussed, a conceptual framework is suggested, and a conclusion is drawn proposing future research directions.

\section{Client Needs Management in Healthcare Facilities: Conventional Practices}

There is a strong relationship between value generation and the effective management of client needs, especially users' needs which demand a better identification and understanding of them during the project definition [9].

In the conventional process of project definition, needs are usually defined in a hurry [22]. They are mainly conceptualized by architects in a single event, based on interviews, examination of client documents, visits to similar facilities, and meetings with client representatives [23-25]. Work sessions are used to confirm the identified needs and information, which can be in the form of correspondence (e-mail), sketches, drawings, etc. Based on the collected information, briefing experts translate client needs into requirements and prepare a brief document [24] which is the official start of the project definition process.

With traditional practices, the brief often uses technical jargon, leaving the functional issues aside [26]. The "voice of the client" is often lost in the process of defining technical or regulatory requirements. Needs are established without the participation of key client stakeholders. What usually seems to happen is that the only client involved in the process is the "paying client". Users are usually neglected [27]. This lack of consideration leads to design mistakes, incomplete designs, misunderstanding of user expectation, and rework. It also leads to healthcare service disruptions in healthcare facilities since usually architects do not have enough information about each user and how they provide the care services [5,28-30]. However, if the architects are ill-equipped to understand the hospital performance and users are not involved in the process, how could they propose a solution that is efficient enough?

Little evidence supports the conventional practices in achieving a match between the future design solution and client needs $[5,31,32]$. Project definition is a difficult challenge in project management, notably in the case of healthcare projects where the environment is uncertain and complex.

According to authors such as Koskela et al. [33] and Pikas et al. [34], the root cause of the problems in conventional project definition management is the fact that it does not base itself on the axes of the production theory, which are transformation (what), flow (how), and value (why). In the transformation view, the process is seen as a transformation of inputs (total transformation) to outputs (elementary tasks) in a temporal manner in 
order to carry out the tasks as efficiently as possible. The flow component conceptualizes production as a dynamic process composed of inspection stages and aims at reducing waste (e.g., delay and wait time). Value generation in production aims at aligning the designed product with client needs [33,35]. These three complementary views co-exist and must equally contribute to project definition.

However, Forgues et al. [4] point out that flow and value are not sufficiently addressed in traditional practices. Tzortzopoulos et al. [35] add that design managers tend to focus on tasks, resources, and contracts which overshadow client requirements. Tzortzopoulos et al. [36] confirm this conclusion and point out that in healthcare projects, the focus is mainly on the transformation view since hospital processes are organized around functional areas that tend to be perceived as isolated. Consequently, the building sector suffers from poor or incomplete project definition, resulting in significant changes in final stages of the project lifecycle, extra costs, and schedule overruns [37].

Furthermore, several authors (e.g., Perminova-Harikoski and Hellstrom [38], Whelton [39], and Kärnä and Junnonen [40]) highlighted that very often, traditional project definition practices are linear and too general and have been criticized for their oversimplification by treating all projects as the same by assuming that "a project is a project is a project" Shenhar and Dvir [41]. However, "One size does not fit all"; projects differ in size, complexity, technology, and risks [42].

Whelton [39] believes that the management style should be adapted to the project complexity and environment. A linear and directive style of management, namely topdown, may be appropriate for organizations with low levels of complexity, but a more adaptive style of management is necessary in projects with high complexity (when different entities are involved), a lot of uncertainty, and a dynamic nature, such as healthcare projects. In such projects, different interactions are required in order to understand each other's needs and make decisions. Furthermore, users have little or no experience with design and construction processes, so the process becomes even more challenging [43].

Evidence suggests that this process cannot be solved by rational methods in a linear and non-participative manner. So, different alternatives to traditional practices, for instance Lean-led Design, have been proposed to deal with it. Involving users in the process seems to be the key to a better project definition [21]. It is expected to help architects to understand user needs better and thus align them with the building design [18].

\section{The Lean Approach in Healthcare Facilities}

While Lean is a general management approach originating from the manufacturing world, it has been increasingly used in the healthcare sector in the past decades.

The adoption of Lean principles in the healthcare operation stage has increased rapidly until now, so much so that Lean healthcare has now become a major strand of research [44]. As a tool, a method, or a practice, this approach is mostly seen as a way to optimize medical processes and facility rooms (emergency department, operating rooms, etc.) in order to increase value for the patients, save on costs, and gain overall efficiency [45-47].

In Quebec (Canada), the Ministry of Health and Social Services has adopted a Lean healthcare approach since 2010, and various sites (hospitals and other clinical facilities) have been undergoing Lean initiatives with the implication of the staff to improve patients and the workers' conditions [48]. Led by the human resources department, workshops targeting specific processes are conducted in order to improve current practices and adapt those to gain efficiency, safety, and comfort. Those Lean initiatives come with a need for change management, as people have to adapt their behaviours to the newly defined processes [49]. Important stakeholders are senior clinicians and clinical leads, as they are influential change agents if new behaviours are to be adopted after implementation, but they sometimes act as antagonists [50].

While the implementing of Lean principles during the operation stage is called Lean healthcare, the implementation of Lean principles during the hospital project definition is called Lean-led Design. The terminology was used for the first time by Grunden and Ha- 
good [19] in 2012. It has been defined as "a systematic approach to healthcare architectural design that focuses on developing, and integrating safe, efficient, waste-free operational processes in order to create the most supportive, patient-focused physical environment possible" Grunden and Hagood [19] (p. 18). Rigorous space planning is sought to deliver the most value to the clients while maximizing space and energy savings.

Lean-led Design represents a participative approach in which design teams work closely with staff to understand the role the environment plays in implementing programmatic and functional space requirements. One interesting tool to organize a Lean initiative is through workshops, or Kaizen, as defined by Grunden and Hagood [19] (p. 16), "In Japanese, Kaizen is typically translated as 'change for the good' and implies continuous improvement. This is a team-based, usually multiway rapid improvement event designed to analyse particularly complex problems that flow across departments. Together, members of the interdepartmental team analyse the current state, find the root causes of problems, develop a vision of the future state, and experiment with new ways to work, implement, and evaluate the new method and sustain it over time."

Another particularity of Lean used during project definition process is the concept of flow which is central to the theory of production [51]. In the United Kingdom, Hicks et al. [11] have conducted specific Lean workshops (called 3P) including different clients to analyse the various flows (patients, staff, families and friends, equipment, medication, and information) while designing healthcare facilities before calculating the square metres and proposing a design solution. The objective of this analysis is to reduce waste and minimize the distances between the different hospital departments.

However, even though Lean-led Design has grown in popularity, little attention has been accorded to the application of Lean principles to the project definition stage in healthcare, unlike in the operation stage, which is why we are focusing on this research.

\section{Materials and Methods}

The purpose of the present study is to figure out how a Lean-led Design approach was applied in order to better align the clients' needs with the design solution, and to develop a framework to advance theoretical knowledge on this topic. To do so, a single case study methodology was used [52], as it suited our overall exploratory endeavour [53]. This methodology can be considered as an appropriate methodology in order to allow a better understanding of the process in a given case [54].

Our case study is a mega-hospital in Québec (Canada), and we focused specifically on the three project definition stages: (1) planning, (2) programming, and (3) schematic design. The reason for selecting this hospital megaproject was based on the specificity of context along with the facility to gain access to data [55]. This project can be considered as "extreme" or "unique" with regard to the particular context that characterizes it and in which strong opposing logic coexist. It represents one of the first-ever single projects that implemented a Lean-led Design approach during its definition phase. It is also one of the biggest hospitals in Canada which aims to consolidate the clinical activities of two existing hospitals on one of the sites by involving a wide range of stakeholders. Another rationale for choosing this case study is because we could study it longitudinally. It helps us to study the same case at various moments in time, and more specifically, it helps us to analyse over time the project definition process and practices.

The research was authorized by the École de technologie supérieure Ethics Committee. Our data is based on a review of approximately 10,000 internal documents. We used different criteria to frame the corpus and chose only important documents produced during project definition. This helped us to reduce the documentation number to 245 .

Furthermore, we guided 22 interviews between 60 to $90 \mathrm{~min}$ with interviewees from diverse profiles involved during the project definition process of the chosen hospital: 3 clinicians, 3 patients, 4 members of the clinical management, 5 project managers, 2 Lean agents, 4 architects, and 1 engineer. 
In fact, three criteria guided the selection of representative profile samples to interview. The first one was to interview at least one person in each category of profile involved in the project definition. In fact, documentation reviewed helped us acquire first-hand knowledge of the organigram of the project studied. Thus, we found three types of profiles involved (Figure 1): (1) project manager team, (2) construction professionals, (3) clients.

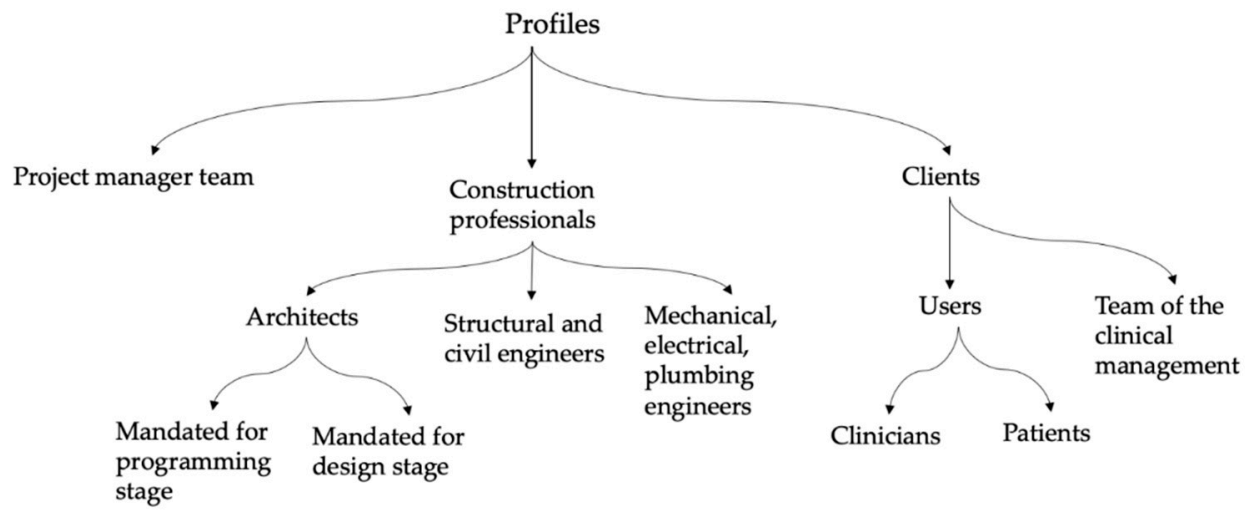

Figure 1. Profiles of interviewees.

The client represents the users (patients, clinicians: doctors, nurses, etc.) and clinical managers. The professionals could be architects mandated for the programming stage, architects mandated for the design stage or mandated for both, mechanical, electrical, plumbing, structural, and civil engineers.

The second criterion was to interview at least an organizer and a participant or observer of each activity realized during the project definition. We also involved a Lean agent. The third criterion was to prioritize those who have organized or participated in more than one project definition activity.

The results were firstly transcribed and secondly coded into thematic categories, using NVivo software. The themes, identified based on the documentation reviewed and highlighted by the respondents, facilitated our understanding of the context and the approach implemented. In order to ensure a common comprehension, validation meetings were organized within the research team and with the clinical manager team of the New Hospital.

\section{Description of the New Hospital}

The New Hospital project is one of the largest in Canada with an estimated cost of approximately CAD 1.97 billion, announced in 2013 to be delivered in 2026 . The complexity of this project is not only due to the need for the construction of new buildings $(180,693$ $\left.\mathrm{m}^{2}\right)$ and the renovation of parts of buildings $\left(27,492 \mathrm{~m}^{2}\right)$, but also maintaining regular operations of the two already functioning hospitals. The merging of two hospitals appeared as a particular occasion to design it around patient needs. However, there were obstacles to it, as the services are offered by the two hospitals since each one has its own culture, and way of working to provide health services. To deal with these issues, a team of the clinical management of the New Hospital was put in place. Their responsibilities were to apply a Lean-led Design approach. The team was co-located near the project site with 220 people (project managers and professionals (architects and engineers)) for the purpose of better collaboration and communication.

A Lean-led Design approach was established through different Kaizen, defined in this context as: "a multidisciplinary consultation workshop that takes several days, in which project managers, clinical managers, [representatives of the] Ministry of Health, clinicians, and patients could participate" [Lean agent]. A Kaizen could take from 1 to 5 successive days. It also places the patients, their family, and their experience at the centre of reflections and decisions. The objective is to create care services focused on patients. 
Thus, seven Kaizen, marking milestones through project definition stages, were organized. However, the first five correspond to project definition (planning and programming stages) (see Table 1). Those five activities have been organized from 2014 to 2015 in order to collect the needs of all client stakeholders. After that, in order to develop the conceptual and schematic designs, a traditional (non-participative) approach was adopted during the schematic design stage, contrary to the planning and programming stages.

Table 1. Different Lean activities and participants of the project definition for the New Hospital.

\begin{tabular}{|c|c|c|c|c|c|c|c|c|}
\hline \multirow[b]{2}{*}{ Stage } & \multirow[b]{2}{*}{ Lean-Led Design Activity } & \multirow[b]{2}{*}{ Date } & \multicolumn{6}{|c|}{ Stakeholders Involved } \\
\hline & & & $\begin{array}{c}\text { Clinical } \\
\text { Managers }\end{array}$ & $\begin{array}{c}\text { Project } \\
\text { Managers }\end{array}$ & $\begin{array}{l}\text { Construction } \\
\text { Professionals }\end{array}$ & Clinicians & Patients & $\begin{array}{l}\text { Ministry } \\
\text { of Heath }\end{array}$ \\
\hline \multirow{2}{*}{1} & Kaizen 1: Guiding Principle & May 2014 & $\mathrm{O}$ & $\mathrm{P}$ & & $\mathrm{P}$ & $\mathrm{P}$ & $\mathrm{P}$ \\
\hline & Kaizen 2: Improving flows & October-November 2014 & $\mathrm{O}$ & $\mathrm{P}$ & & $\mathrm{P}$ & $\mathrm{P}$ & $\mathrm{P}$ \\
\hline \multirow{3}{*}{2} & Kaizen 3: Organizational chart & January 2015 & $\mathrm{O}$ & $\mathrm{P}$ & $\mathrm{P}$ & $\mathrm{P}$ & $\mathrm{P}$ & $\mathrm{P}$ \\
\hline & $\begin{array}{c}\text { Kaizen 4: Implantation } \\
\text { hypotheses }\end{array}$ & May 2015 & $\mathrm{P}$ & $\mathrm{P}$ & $\mathrm{O}$ & $\mathrm{P}$ & $\mathrm{P}$ & $\mathrm{P}$ \\
\hline & Kaizen 5: Operating modes & September-December 2015 & $\mathrm{P}$ & $\mathrm{P}$ & $\mathrm{O}$ & $\mathrm{P}$ & $\mathrm{P}$ & $\mathrm{P}$ \\
\hline 3,4 & - & & & & & & & \\
\hline 5 & Kaizen 6: Transformation * & \multirow{2}{*}{ From 2016 to 2025} & $\mathrm{O}$ & $\mathrm{P}$ & & $\mathrm{P}$ & $\mathrm{P}$ & \\
\hline 5 & Kaizen 7: Transition * & & $\mathrm{O}$ & $\mathrm{P}$ & & $\mathrm{P}$ & $\mathrm{P}$ & \\
\hline
\end{tabular}

O: organizers. P: participants. 1: planning stage, 2: programming stage, 3: schematic design stage, 4: design stage, 5: transition stage. ${ }^{*}$ Kaizen 6 and 7 realized based on an iterative process.

In the next section, the results including the process followed by the New Hospital are presented with more details.

\section{Results}

This section is structured in two parts. First, the detailed steps taken for the overall Lean-led approach are presented. Secondly, the importance of stakeholder representativeness during the project definition is presented.

\subsection{Steps of Lean-Led Design Approach Undertaken by the New Hospital}

In order to align client needs with the conceptual design solutions of the New Hospital project, eight important steps were followed:

1. Definition of a common vision and guiding principles (planning stage: Kaizen 1);

2. Identification of user needs based on flow analysis (planning stage: Kaizen 2);

3. Development of the organizational chart based on proximity links (programming stage: Kaizen 3);

4. Development of hypotheses for implantation on site (programming stage);

5. Evaluation of the hypothesis based on an evaluation grid (programming stage: Kaizen 4);

6. Definition of operating modes (programming stage: Kaizen 5);

7. Development of conceptual and definitive designs (schematic design and design stages);

8. Preparation of the transformation and the transition (transition stage: Kaizen 6 and Kaizen 7).

\subsubsection{Definition of a Common Vision and Guiding Principles (Planning Stage: Kaizen 1)}

One of the first priorities of founding a new hospital is to create a unified vision of the project between teams from both of the merging hospitals. As a clinical manager highlighted:

"This is not easy, because even doctors in the same specialty have different points of view: clinical and technical sides. Each hospital has a different way of working". 
Thus, Kaizen 1 guiding principle took place in May 2014. More than one hundred and sixty people participated, including clinical managers, clinical and medical leaders of the hospital, project managers, and external observers. They were seated on seventeen round tables and were invited to reflect on six major themes proposed by the animators: 1-patient experience and access to services, 2-care and best medical practices, 3 -instruction, research, and evaluation of health technologies, 4-environment and support services, 5-human resources, 6-hospital as a corporate citizen.

Several ideas were proposed via brainstorming and transcribed, from which twentyfive guiding principles were deduced. These guiding principles constitute the benchmarks of guidance in consistent decision making not only in the project definition phase but also in the design and construction phases, as this quote illustrates:

"We have developed 25 guiding principles to help us make better decisions afterwards" [clinician].

Therefore, the first Kaizen represents an important step as it provides the widest possible consensus on the project's objectives and its clinical significance on the one hand, and creates a commitment and conviction to the project for the participants on the other hand. It is therefore an essential condition for the development of the clinical plan to realize the second Kaizen. In fact, the clinical plan document, required by the Ministry of Health and Social Services of Quebec, provides a snapshot of the current state of care and services and gives an estimate of clinical activities in the next 15 or 20 years to determine the future potential needs of clients.

\subsubsection{Identification of User Needs Based on Flow Analysis (Planning Stage: Kaizen 2)}

After defining a common vision between the different stakeholders, the second step represents the documentation and the analysis of the different hospital flow: patients, staff, families and friends, equipment, medication, and information. The importance of this analysis is to align and improve the current flows before calculating the square metres or proposing a conceptual design. It represents, in fact, one of the major distinctions between the conventional and the Lean-led Design approach.

In the New Hospital context, the hospital flow analysis exercise was realized in two parts during the Kaizen 2 activity. The first part focused on patient and clinician flows and the second part focused on medicines, materials, and information flow. The first part was conducted in five successive days with the participation of more than fifty people, including doctors, clinical managers, unit heads of both hospitals, project managers, and three individuals with experience in patient care. These participants were divided into four interdisciplinary groups with representatives of each hospital. The objective was to represent the actual care flow of five fictitious patients which were representatives of each sector for each hospital. Based on these specifications, several problems were identified to think about the best way to create unified trajectories and organize the different care sectors. This reflection was based on the twenty-five guiding principles that had been identified during the Kaizen 1, such as putting the patients at the centre of the care, making staff and technical equipment available to meet their needs:

"We wanted to align the hospital services as we could, in order to provide better care for the patients." [clinician].

The second part of Kaizen 2 focused on logistic processes, namely the other three flows: medicines, material, and information. It was organized in four days with the participation of more than forty-five people including project managers, clinical managers, ministry of health representatives as observers, and staff from both hospitals from different sectors such as laboratory, technical and logistical services, IT (Information Technology), and food. Based on the output of the first part of Kaizen 2, the participants tried to unify the flows of both hospitals and create a shared vision for the first new service group that will ultimately be embodied on the site. As these quotes illustrate: 
"The Kaizen facilitated the communication among us and the development of a shared vision" [clinician].

"The objective of the Kaizen is to create a common vision of the New Hospital care services. Also, it aims at facilitating the understanding of the choices and the decisions made by the architects." [clinical manager].

Both the users and the members of the clinical management team expressed that the Lean activities meaningfully helped them reach a consensus about the project objectives, choices, and decisions.

Thus, complementary to this first vision of the physical layout, a new vision emerged in the process to deliver clinical and logistic services to support new equipment and major clinical improvements. Based on that, a clinical plan was co-created by users, members of clinical management of the New Hospital, and architects. In fact, at the beginning the clinical plan was written only by external persons, however, "They didn't write it well because they didn't understand the clinical areas very well" [member of the New Hospital clinical management team]. That is why it was written again, involving users.

After an analysis of the clinical plan of the New Hospital, the experts of the Ministry of Health made decisions regarding the needs expressed with regards to the volumes of activities, future directions, and proposed operating modes. Some needs were reduced to take account of budgetary constraints. As the clinical plan had been approved, the next activities (Kaizen 3 to 5) were conducted in order to develop the functional and technical program (FTP), which identifies the requirements relating to the functional, operational and physical organization of the premises and determines the overall budgetary envelope to achieve it. It is therefore an important tool to generate preliminary architectural design plans and produce the opportunity file required to approve the project and move to the planning stage at the Quebec Council of Ministers. To do so, the next step was to develop the organizational chart.

5.1.3. Development of the Organizational Chart Based on Proximity Links (Programming Stage: Kaizen 3)

After aligning the flows of both hospitals, the third step aimed to identify needs of proximity and prioritize them in order to develop the organizational chart, as highlighted by a member of the New Hospital management team:

"We prioritized the types of clientele and not sectors. For example, clients who need critical care, followed by hospitalization and, finally, outpatient care."

To do so, Kaizen 3 was organized by the clinical managers. It involved seventy-four participants including clinicians, patient representatives, and project managers. At this stage, designers mandated for the programming stage had also integrated the project definition process and observed before starting the organization of the next activities.

Thus, the objective of Kaizen 3 was to analyse, document, and prioritize the needs of proximity between the areas projected in the clinical plan and their importance according to the flow of the patients, already identified in Kaizen 2, and taking into account the clinical and technical constraints. Moreover, at this stage, the concept of scale (area, square metres) was introduced. In order to facilitate the perception of the size of the spaces for users, the organizers of Kaizen 3 used reference points such as a football field, an ice rink, etc. Thanks to this awareness of the dimensions of the sectors, participants were able to quickly see the need to reduce patient's movements, and thus, organize and group the essential activities. On this organizational basis, three types of links were identified between the sectors: critical, essential, and important or desirable. These links were assessed using a weighted and objective grid to develop the organizational plan. Subsequently, this pattern was improved during other workshops by the clinical managers in collaboration with the logistical support and hospitalization team. The aim was to achieve the best possible organizational plan. Thus, all of this work helped as the basis for the development of the hypotheses of implantation of the new buildings on the site. 


\subsubsection{Development of the Hypotheses for Implantation on Site (Programming Stage)}

Although the clinical management team continued to attend and supervise the process of project definition, at this step, architects were leading it. They had translated the organizational scheme delivered during Kaizen 3 into five different hypotheses for the location of the different sectors of the site. These were developed from dozens of studies by testing the different ways of locating the sectors and taking into account the constraints of the land as well as the existing buildings on the site. These hypotheses were evaluated in the next step by the different users.

\subsubsection{Evaluation of the Hypothesis Based on an Evaluation Grid (Programming Stage:} Kaizen 4)

In order to facilitate the evaluation of the five propositions and identify the one to retain for the rest of the project, an evaluation grid was proposed by the architects based on clinical and technical criteria. These criteria represent the adjustment of the twenty-five guiding principles which were developed during Kaizen 1 plus the links between sectors which were developed in the previous Kaizen. The reason for modifying the guiding principles (criteria) was related to their operationality, as explained by an architect:

"The 25 principles are not very operational. We had to translate them into more technical design terms to facilitate the alignment between the needs and the design solutions" [architect mandated for the programming stage].

Thus, after developing the evaluation grid, Kaizen 4 was organized by the architect mandated for the programming stage. This Kaizen empowered users by engaging them in the process of decision making. It also involved the project managers and the clinical managers in the reflection. Based on this initial evaluation, architects reviewed the implantation hypotheses and after two days of work, proposed two more, since users have rejected all the first proposed hypothesis. The latter two were re-evaluated and commented on, which allowed for the development of a single reference hypothesis for the implantation of the different sectors of the hospital. An architect noted:

"We developed an evaluation grid that helped us to evaluate the hypotheses proposed of building implantation on the site, and also evaluate the degree of the users' satisfaction regarding these solutions. Thanks to the different evaluations, we proposed an adjusted hypothesis that achieved a 90\% degree of satisfaction of the users."

This adjusted hypothesis was not a definite one, but the starting point of a process of continuous improvement that took place from May 2015 to November 2015. In parallel, a meeting was held in May 2015 with residents of the neighbourhood in which would be located in the New Hospital, in Maizerets district. The objective was to present the studies carried out and hear their concerns regarding the implementation of the New Hospital.

\subsubsection{Definition of Operating Modes (Programming Stage: Kaizen 5)}

This step of the process aimed at comparing and aligning current operational clinical methods with the implementation hypotheses developed during Kaizen 4. Thus, several complementary workshops were organized with the architects after Kaizen 4. Here the objective was to continue to improve and adjust baseline implementation hypotheses by exploring the operating methods of about 20 hospital sectors. This allowed professionals to propose physical planning standards, confirm the revised operating model, and establish a list of validated and optimized needs (spaces, resources, and main required equipment).

Following all this pre-work, architects organized Kaizen 5, in five consecutive phases between September and November 2015 to continue the validation and the alignment of the business models regarding each sector. More than four hundred participants including clinicians, managers, patients, and members of the clinical management team were involved. The objective was to continue the validation and the alignment of the business models of the sectors, as explained by an architect: 
"The objective is to validate the positioning of sectors and premises in relation to each other. This positioning was the basis for carrying out the plans."

To do so, the first part was based on optimizing patients' experience and use of space, which aligned and validated the whole [or part of] the operation model of different sectors. This exercise was realized by using ten full-scale mock-ups. The idea was to reproduce standardized rooms in an environment mock-up on a small scale to facilitate the understanding of spaces for participants, using removable walls. The rooms presented in the full-scale mock-up were often "standard rooms" or particular rooms, for instance, rooms in a care unit, intensive care unit, an examination room, etc. The second part of the Kaizen was intended to allow the participants from the previous Kaizen to appreciate the evolution of the improved organizational plan of the new hospital and to provide feedback. In addition, it ensured that the implementation hypotheses regarding the site were aligned with the user needs (developed during Kaizen 4). At the end of this step, an open house event was organized to let a wider range of audiences visit the full-scale models and become familiar with the Lean-led approach.

As a result of this iterative and progressive work, the functional and technical program (FTP) was drafted by the designers mandated for the programming stage and submitted to the Ministry of Health. However, this document needed to be re-written, after its analysis by experts of the Ministry of Health and Social Services of Québec. While project managers claim that the problem was related to the lack of knowing about how to develop such a document, members of the New Hospital clinical management team explain that the problem was more related to the confusion between the traditional and the Lean-led approach:

"There was a confusion between our two ways of delivering our thoughts: traditional vs. Lean. At the beginning we had drafted a Lean document, but the Ministry was not satisfied. We therefore improved it to go for the traditional side" [member of the New Hospital clinical management team].

After this modification, the FTP was approved. However, this document is not static: "We changed parts of the FTP to ensure precisely the evolution over time of the technology and the methods that doctors may have. It is a living document and not a static one" [mechanical engineer].

In the summer of 2016, the government approved the project so that it could go forward to the design phase with the elaboration of the plans and specifications.

5.1.7. Development of Conceptual and Definitive Designs (Preliminary Design and Design Stages)

The request for proposals was launched to select new professionals for the project in order to develop architectural plans. Unlike the previous stages, in the conceptual design stage as well as the design stage, a non-participatory approach was used, so users were not involved:

"We are returning to the traditional way of drawing up plans, because architects feel more confident with this way of working than with integrated design. But it's also because of the budget" [member of the New Hospital clinical management team].

In fact, some designers claimed that in the New Hospital project, there was no necessity to implement an integrated design process. However, while designers claimed that there is no necessity to implement a participative approach at this stage, clinical managers argued that the chosen traditional approach was not the best decision made. In fact, it could even negatively affect what has been done during the programming stage through the Lean-led approach and thus may lead to misalignment between the previous and future decisions. For instance, during the schematic design stage, a loss of acquired knowledge was identified among users since they did not understand architects' decisions, even though a big effort 
was made during Lean activities to share knowledge among them. A design professional mandated for the design stage explains:

"In fact, we felt that users never trust us. They don't understand what we do and why we take these decisions, even if we explain to them the structural and the mechanical constraints."

Furthermore, several problems have been identified between programming and schematic design stages. The transition between the two stages was problematic since not only the design professionals but also the general approach had changed thus different hindering factors were identified, for example, loss of information.

To deal with this issue, clinical managers suggested the use of Integrated Design Process to gather the project team members through workshops to stimulate innovative solutions starting from the end of the project definition [4]. The idea was to continue with the same participative perspective as in the planning and the programming stages.

By the end of the schematic design and design stages, the established departments were no longer movable, and the design was frozen.

5.1.8. Preparation of the Transformation and the Transition (Transition Stage: Kaizen 6 and Kaizen 7)

This project was realized in a fast-track mode and divided into different components. Once the architectural plan of the first component was finished, new Lean activities, Kaizen 6 and Kaizen 7, started in parallel to the design stage. This means that the Lean approach did not end at the project definition stage. However, unlike the previous Kaizen, they were not very often organized since they are based on an iterative process depending on the progress of the project and specific expressed needs.

In such a mega-hospital, preparing for moving to the new building is a complex process that takes years since the different departments existing are interconnected. A lack of preparation may lead to several problems:

"For example, the fact that the other hospitals in Quebec had not transformed their practices created a lot of problems during the transfer of activities (the drugs are not unified, the sheets either, etc.) ... It was important for us to learn from their experience" [member of the New Hospital clinical management team].

The objective of these Lean activities was thus to prepare both the transformation (Kaizen 6) and the transition (Kaizen 7) of the hospital staff. Other objectives were to analyse the current operating modes of the two hospitals with regards to the envisioned ones in the New Hospital, and to determine the necessary transformations in order to gradually unify the different processes for migration. In such a mega-hospital, the transformation and the transition are complex processes and can take years of preparation since the different existing departments are interconnected. As one of the specificities of the New Hospital project is the phased delivery into different building components, it therefore requires a solid transition plan composed of multiple transfers of care services. While in the transformation process, the focus is on understanding how to transform the activities of both hospitals and align them with the new designs so that after moving to the new setting, there will be no major hardships; the main question in the transition process is: What are the steps to follow in order to move out to the new setting while keeping the continuity of care for patients?

Therefore, from 2016 until the end of the construction planned in 2026, the clinical management team would continue to support this overall transformation by organizing punctual Lean activities in order to prepare the transition and transfer to the new installations.

Next, we turn to describe one of the main themes that emerged from the Lean-led process for project definition: the importance of stakeholder representativeness. 


\subsection{The Importance of Stakeholder Representativeness}

As Lean activities unfolded, the project developed, and various stakeholders participated in the process. Here, we shed light on three main points. The first is the basic premise that project definition should be patient focused. Kaizens included real patients that were encouraged to participate and give testimonies to all participants. It was even acknowledged that they helped raise awareness about some points that were not clear at the beginning to the clinical and the professional teams. The objective of the group was to put the patient at the centre of the discussions:

"In fact, what we want is to improve the care and services for the patient and then put the walls around" [clinician].

As the first activities specifically targeted patient trajectory within the hospital and the synchronization of activities with each other, this helped to identify all potential issues. Some testimonies relate that it was sometimes challenging to maintain the focus on patients throughout all activities for the definition of the project. Yet, as discussions unfolded in various workshops, there was always someone to ask the question whether this was the best thing for the patients or not, ensuring a collective conscious project development with that goal in mind.

The second point that proved to be extremely important was to get a wide and representative stakeholder involvement of the two hospitals to be merged in the new hospital complex. The expertise of all sectors was mobilized to generate an integrated vision. Clinicians, managers, patients, professionals and support services staff were mobilized to achieve a common alignment. In addition, as reported by the interviewees, Lean activities were a golden opportunity to build synergies among the stakeholders:

"Making us work together during these workshops created synergies and a trust environment" [patient].

The stakeholder involvement was not always easy to manage, and one of the challenges of the transition team was to allow the different clinical teams to maintain their overall vision of the project. Yet, organization of the open house activity in Kaizen 6 enabled a wider communication with all stakeholders, providing moments for discussions and exchanges, so that all could position themselves regarding the proposed hypothesis.

The third point was about stakeholder collaboration. The aim of the first activities was to bring a consensus regarding the main principles among all participants in order to progress collectively to define the project. Another important aspect was that everybody had to develop a common understanding regarding the project; the steps taken so far and the ones ahead, and workshops seem to have favoured this. Improvement has been noted by several participants during the course of the activities. At first, participants referred to their respective hospital, to gradually develop a collective identity, an "us" for the new hospital to be. The participants were deeply involved in the discussions; all had the same goals in mind about the continuous improvement of care. A collective approach allowed all to become aware not only of what their individual or sectoral needs were, but also of what the other needs are, so that they could prioritize them through a consensus. When different opinions were expressed and consensus could not be achieved, different scenarios were developed and explored for further selection of the best possible solution. Participants noted the evolution of the collaborative process:

"We see a nice evolution of the teams, which started from their own disciplinary needs to connect later with patient needs along with those of all other sectors" [clinician].

Participants learned about the reality, needs and concerns of other sectors. They also felt that they were at the centre of the project, which had to be defined, as they believed, in a bottom-up approach.

We now turn to discussing those findings in light of the relevant literature. 


\section{Discussion}

This research reveals that alignment between client needs and design solutions is a potent source for users' value generation and thus project success. To that end, we developed a conceptual framework (Figure 2) based on the case study which summarizes the principal steps of the Lean-led Design approach adopted in this project.

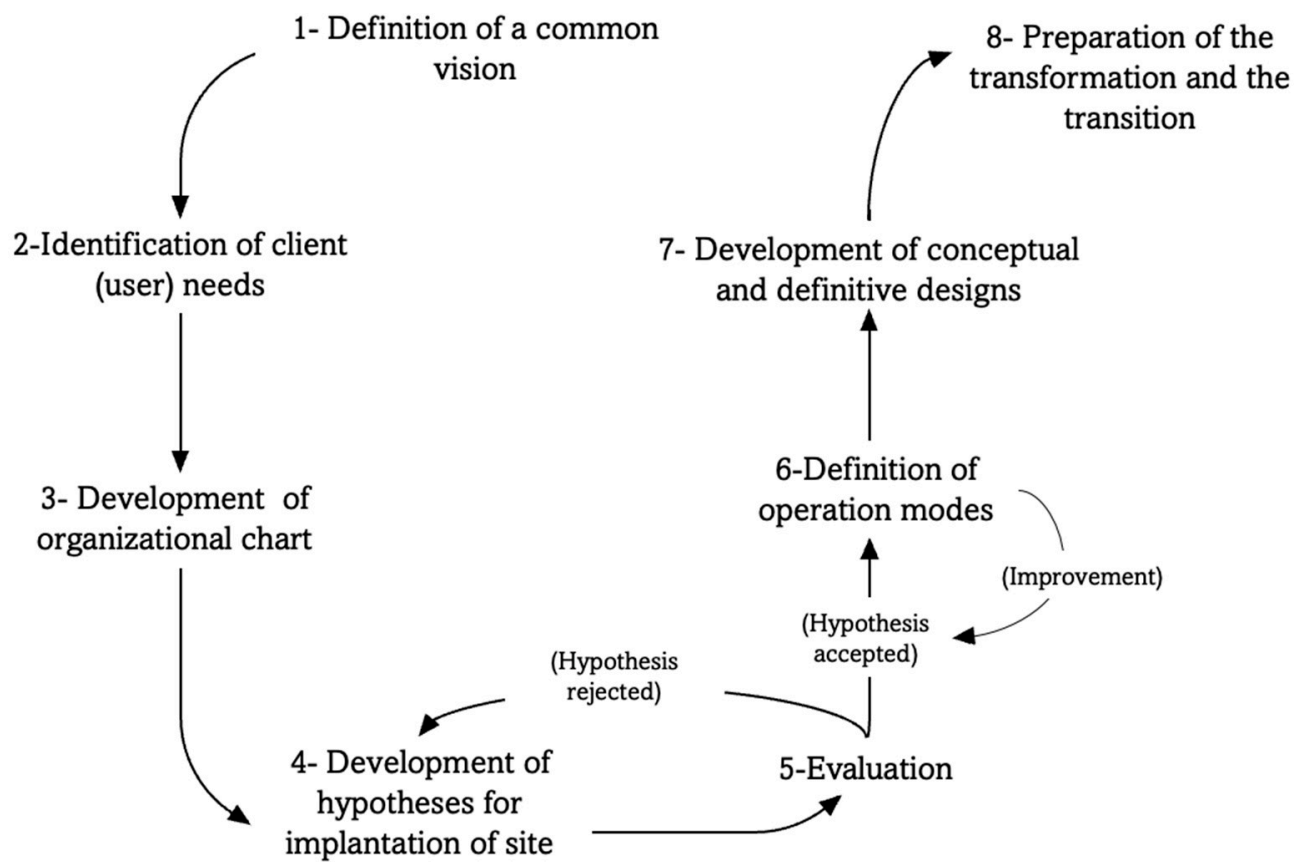

Figure 2. Steps in the implementation of a Lean-led Design approach.

The proposed framework starts firstly by defining guiding principles and a common vision between the different stakeholders in order to create a shared understanding among them. By working together, every participant tries to share their views about the project and make sure that they are well understood by others. This gradually leads to the development of a shared understanding and mental alignment among them and thus motivate the users to be more committed to the project. However, more important than sharing a vision, its continuity throughout the whole process of project definition is important since a lack of continuity can undo all the previous understanding and thus the consensus. Actually, changes in personnel and users can impact this continuity.

The second step represents the identification of user needs. Contrarily to a traditional approach that begin with estimating the areas needed for each hospital service, with Leanled Design, the architects start with analysing and improving the hospital flows. Based on suggestions by hicks et al. [11], in the New Hospital project, construction professionals and users jointly analysed the main trajectories and flows, including those of patients, the medical staff, information, medicines, etc. Subsequently, they were asked to identify problems and propose improvements, taking into account the patient trajectories in the first place. This problem-solving mode allowed participants to better understand and visualize project constraints and scopes, letting them have a more holistic view of the relationship between spatial configuration and conducting clinical activities.

The third step is about developing an organizational chart based on proximity links. The objective here is to classify the types of links (critical, essential, important or desirable) between the different department and hospital services. This classification should help the architects to make the best decisions when developing the hypotheses for implantation on site.

The fourth step consists of developing different hypotheses for implantation on site. It is about testing the different ways of locating the sectors on the site based on the organizational chart. These hypotheses should be evaluated by different users during the fifth 
step based on an evaluation grid (developed based on guiding principles and proximity links). If users validate the hypothesis, the architects could define the operation mode of each service (spaces, resources, and main required equipment), if not, they should adjust the different hypotheses until achieving users' satisfaction.

Once the operation mode is defined, validated and evaluated by users, the step seven starts. The evaluation of operation mode of services could be realized by full-size mock-ups in order to facilitate the visualization and thus the understanding of the spaces. It also important to mention here that based on the operation modes defined, the hypothesis previously accepted could be adjusted again.

After that, during the seventh step it could be interesting to continue with an integrated process design by involving not only designers but also construction engineers as suggested by authors such as Forgues et al. [4]. Including all disciplines should reduce waste and generate a better value. Involving users, during this stage, is also recommended by authors such as Tzortzopulos et al. [17], Fuentes et al. [56], Trischler et al. [57] and Chbaly [58], to promote a democratic design process. However, since the building design process requires a technical and a specific knowledge that users do not usually have, Caixeta et al. [18] argued that the best suited level of user involvement at this stage are "consultative" and "informative." This means that users could be less involved than the first two stages (planning and programming).

A Lean-led Design approach is a continuous and iterative process. It is carried out in a non-linear and flexible fashion as other methodologies such as with design thinking or co-design [59]. It is not limited to the project definition, but it could continue until the time of construction and transition to the new buildings [7]. The goal is not only to create spatial configurations to facilitate efficient operations, transformation processes and transition, but also to review needs of users, that could evolve over the years, at each stage of the project.

Based on our case study, all these steps could be realized through the implementation of different Kaizen. This result is in line with the proposition of Grunden and Hagood [19] who considered the Kaizen as a Lean tool to cross departmental barriers. Each Kaizen could be structured and adapted according to needs: the objective, the number of days required, the number of participants, etc. Unlike the definition of Kaizen, proposed by Landry and Beaulieu [60], which limits the number of participants to twelve, the ones implemented in this project involved more than four hundred people. Meanwhile, patients in addition to medical staff and managers were involved in the consultations. At least one patient representative was present for each Kaizen. Thus, a Lean approach must be adjusted to the context of the organization and the actors' needs if it is to be successful [49]. There is no single recipe, especially when Lean is incorporated in the definition of a large-scale project such as the construction a new hospital or a merger of two organizations. Further, in order to develop an approach adapted for the specific needs of the project/organization, it is suggested that benchmarking activities be conducted to learn how others have worked, what lessons they have acquired, so that a shared vision can emerge from this understanding. As an example, the clinical manager has made several site visits in other organizations and shared with people who had been involved in Lean endeavours and other medical innovations: the Calgary Hospital (for critical cares), the Houston Cancer Institute, Ottawa and Sherbrooke Hospitals, along with Montreal's CHUM and CUSM to learn from their recent transformation experience.

Furthermore, Lean-led Design is considered as an inclusive approach with several advantages and contributions to project definition. In fact, the implementation of different Kaizen reduced the complexity of defining the hospital needs. It also promoted an active dialogue with a large number of clients (users). These different interactions between architects and users make it possible to take into account various opinions expressed for the purpose of defining both functional and technical requirements. Moreover, the involvement of users does not end with the definition of the project but continues throughout the project.

In the New Hospital, the project stakeholders developed a shared vision and a common ground through project definition. As suggested by Hietajärvi and Aaltonen [61], the 
following key activities supported this collective formation: articulating a shared vision, converging to mutual principles and legitimizing activities. Managing collaborative space has proven to be challenging in complex projects such as hospital constructions; thereupon, Kokkonen and Vaagaasar [62] suggested the adoption of management practices such as creating shared collaboration practices. The clinical managers have been important catalysts and leaders in this responsibility, as they worked as change agents, first to involve the main stakeholders and second, to guide them through project definition activities. Project participants developed their understanding and a shared identity in order to communicate and legitimate this project with their colleagues, becoming themselves change agents. The Lean-led Design approach allowed participants to acquire knowledge in different domains such as architectural design and other medical specializations, to translate their needs and develop an emerging shared culture and knowledge. From pluralistic views and knowledge, a configuration of shared organizational capabilities emerged as participants developed a sense of ownership for the project [63]. Most importantly, a focus on patients was developed and maintained through iterative development cycles allowing for staged reflection and learning nodes [64]. Eskored et al. [2] proposed that involvement in a project could lead to more engaged and satisfied stakeholders, yet this also may result in client dissatisfaction if their demands and needs are not achieved. So far, the presented case underlined that stakeholder involvement was generally perceived positively, as a collective intelligence developed, democratizing the process and fostering innovations.

While specifying user needs is a daunting task, Smith et al. [65] and Thyssen et al. [66] have argued that practical workshops incorporating client value, facilitated the conceptual design of construction projects. Thus, project definition with client involvement favours value generation through relational and human aspects [67]. Team harmony increases through time, simplifying project definition. The Lean-led Design approach, based on value delivered to patients, is an interesting model for stakeholder cooperation and an important mechanism for delivering value in healthcare [7]. With such a participatory approach, the client (users) plays a significant role in the design process and in the delivery of the value outcomes $[43,56]$. Further, according to Luotola et al. [68] involving the clients in the process may be firstly undertaken to deal with uncertain and complex contexts more than simple ones.

Applying a Lean-led Design approach changed the distribution of power between users and designers, since users obtained an understanding of the working scenario and were seen as co-designers during the two first stages (planning and programming). It is a is a user-driven process. With this participatory approach, users have real influence on a project by being part of the design process [25]. An example of that is during the Kaizen 5, when user participants rejected the scenarios suggested by the designers, which is a quite unusual situation in conventional practices.

User (actual or future) participation is certainly necessary for alignment between stakeholders. As cited by Eriksson et al. [69], there is an agreement that involving users during the early stages adds value to the design process. Users are seen by different authors (e.g., Eriksson [70] and Hannula and Irrmann [71]) as a source of information and knowledge for the architects. Using their experiences should help the architects to provide the best solutions [59]. Nonetheless, it is a two-edged sword because a large involvement of users may hinder alignment. Management of this mobilization is not always easy to maintain [7]. Tzortzopoulos and Cooper [22] argued that project definition is seen as a complex process which poses difficult managerial problems. There are often conflicting needs which demand an effort to recognize them. Hence, it appears important to involve clients in an appropriate way and time. However, according to Steen [72], this required extra coordination and efforts, and training to manage a rigorous and collaborative process in an uncertain and complex environment.

Another challenge that was highlighted by authors such as [70] when implementing such participatory approaches is about the architects' role in the process. According to authors including Steen et al. [72] and Caixeta et al. [73] the challenge for the architects is 
to let users feel that they have an impact on the design solution without losing the whole control of the process.

Furthermore, implementing such a participative approach requires sufficient resources (human and budgetary) and time as highlighted by authors like Lee and Egbu [74] and Latham [75]. There are costs associated with the organization of the workshops and the tools used during the process. Another challenge is about identifying the appropriate people (for instance: users, employees, etc.) to engage in the appropriate project definition stage and give them the appropriate role in the process [72].

Implementing a participatory approach is also quite challenging in a context with different regulations and departmental requirements. As explained previously, there is a contradiction and a "clash" between two ways of working, the traditional required by the Ministry of Health, and the Lean-led approach. This clash can sometimes make the process effortful and challenging. As an example, the FTP was rejected for the first time by the ministry because it was written as a Lean FTP and not in a traditional way.

In summary, both research questions have been covered in this section. The first one was covered by presenting the eight key steps in order to implement a Lean-led Design approach. The second research question examines the contributions and benefits of this participatory approach to project definition. To answer this question, we concluded that implementing a Lean-led Design approach can help to improve managing the project definition process more effectively and efficiently as well as decision making. Unlike the conventional practices where design is managed from architects' perspective only, here the design is managed from both architects' and users' perspectives. By involving key clients, the designers reach a clear understanding of users' activities in a detailed level. This can facilitate the meeting of user expectations and ensure the delivery of buildings with a better fit for use and purpose, which can consequently minimize waste (e.g., patient wait times) during the health care episode and increase value to final users.

\section{Conclusions}

This research aimed to understand how a Lean-led Design approach could be implemented in order to help improve alignment between client needs and design solutions during the project definition in a complex context. The results and discussion have brought forward important considerations regarding the role of early stakeholder involvement by illustrating the contribution of Lean-led Design to project definition. Participants underlined that the Lean-led Design promoted a dialogue between architects and users, favoured the evolution of a common understanding and during the process, early opposing stakeholders could become positive change agents.

Results of the present research deepen our understanding of the project definition phase of healthcare projects, such as merging and construction of a hospital. It also provides a conceptual Lean-led design framework for further development that could help practitioners to implement effectively the approach in complex projects. Thus, it may help to enhance the project definition process.

However, the main limitation of this study is that the conceptual framework developed in this research should not be replicated without taking the overall context into consideration. In fact, the framework was proposed based on a single case study (healthcare projects). At the time of writing, it has not been evaluated in further projects or contexts. With regards to future investigations, this framework needs to be evaluated in similar or different building projects, for instance airports, where various stakeholders are involved.

Furthermore, due to time limitations we could not investigate whether the alignment between user needs, and if the final delivered outcome were to be achieved. The project is still between the design and construction stages. This means that we cannot evaluate if, according to users, the New Hospital buildings are fit for the purposes and intended use or not. Therefore, it could be very informative to investigate this matter in a further study.

Another possible fruitful research avenue would be to study more specifically the role of socio-material artifacts in the process, how they contribute to a shared understanding, 
and translation from diverse knowledge domains such as architectural conception and clinical needs. Finally, this study may benefit from a longer-term perspective, since the project will continue, and new insights could be acquired over time.

Author Contributions: H.C. did most of the data collection and the writing of the paper. M.B. worked closely with H.C. to ensure validity and reliability of the results and wrote the first draft of specific sections of the paper. All authors have read and agreed to the published version of the manuscript.

Funding: This research was sponsored by the Natural Sciences and Engineering Research Council of Canada. This research was also paid for in part by a grant from Fonds de recherche Société et culture, Québec (2020-NP-266212).

Institutional Review Board Statement: The study was conducted according to the guidelines of the Declaration of Helsinki, and approved by the Institutional Review Board (or Ethics Committee) of École de technologie supérieure (protocol code H20181105, 15 January 2019).

Informed Consent Statement: Informed consent was obtained from all subjects involved in the study.

Data Availability Statement: Data supporting reported results are available from the corresponding author on a reasonable request. The data are not publicly available due to ethical restrictions.

Acknowledgments: The authors thank Daniel Forgues and Samia Ben Rajeb for their useful comments and guidance on a previous draft of this paper.

Conflicts of Interest: The authors declare no conflict of interest.

\section{References}

1. Pitsis, T.S.; Sankaran, S.; Gudergan, S.; Clegg, S.R. Governing projects under complexity: Theory and practice in project management. Int. J. Proj. Manag. 2014, 32, 1285-1290. [CrossRef]

2. Eskerod, P.; Huemann, M.; Savage, G. Project Stakeholder Management-Past and Present. Proj. Manag. J. 2015, 46, 6-14. [CrossRef]

3. Schouten, H.; Heusinkveld, S.; van der Kam, W.; Benders, J. Implementing lean-led hospital design; lessons gained at a pioneer. J Health Organ. Manag. 2020, 35, 1-16. [CrossRef] [PubMed]

4. Forgues, D.; Brunet, M.; Chbaly, H. Lean-led, evidence-based and integrated design: Toward a collaborative briefing process. In Proceedings of the International Conference on Cooperative Design, Visualization and Engineering, Hangzhou, China, 21-24 October 2018.

5. Pikas, E.; Oehmen, J.; Koskela, L.; Thuesen, C. A new framework for construction project definition stage. In Proceedings of the DS 92: DESIGN 2018 15th International Design Conference, Dubrovnik, Croatia, 21-24 May 2018.

6. Antillon, E.I.; Molenaar, K.R.; Javernick-Will, A. Evaluating the Effect of Contract Timing on Lifecycle-Design Innovation in Public-Private Partnerships: Comparative Case Study of Highway Projects. J. Constr. Eng. Manag. 2017, 143, 05016023. [CrossRef]

7. Chbaly, H.; Forgues, D.; Ben Rajeb, S. Towards a Framework for Promoting Communication during Project Definition. Sustainability 2021, 13, 9861. [CrossRef]

8. Soliman-Junior, J.; Formoso, C.T.; Tzortzopoulos, P. A semantic-based framework for automated rule checking in healthcare construction projects. Can. J. Civ. Eng. 2020, 47, 202-214. [CrossRef]

9. Baldauf, J.P.; Formoso, C.T.; Tzortzopoulos, P.; Miron, L.I.G.; Soliman-Junior, J. Using Building Information Modelling to Manage Client Requirements in Social Housing Projects. Sustainability 2020, 12, 2804. [CrossRef]

10. Apaolaza, U.; Lizarralde, A. Managing Multiple Projects in Uncertain Contexts: A Case Study on the Application of a New Approach Based on the Critical Chain Method. Sustainability 2020, 12, 5999. [CrossRef]

11. Hicks, C.; McGovern, T.; Prior, G.; Smith, I. Applying lean principles to the design of healthcare facilities. Int. J. Prod. Econ. 2015, 170, 677-686. [CrossRef]

12. Jiménez, V.; Afonso, P.; Fernandes, G. Using Agile Project Management in the Design and Implementation of Activity-Based Costing Systems. Sustainability 2020, 12, 10352. [CrossRef]

13. Becker, F.; Parsons, K.S. Hospital facilities and the role of evidence-based design. J. Facil. Manag. 2007, 5, 263-274. [CrossRef]

14. Klevens, R.M.; Edwards, J.R.; Richards, C.L., Jr.; Horan, T.C.; Gaynes, R.P.; Pollock, D.A.; Cardo, D.M. Estimating Health Care-Associated Infections and Deaths in U.S. Hospitals, 2002. Public Health Rep. 2007, 122, 160-166. [CrossRef] [PubMed]

15. Lake, E.T.; Sanders, J.; Duan, R.; Riman, K.A.; Schoenauer, K.M.; Chen, Y. A Meta-Analysis of the Associations between the Nurse Work Environment in Hospitals and 4 Sets of Outcomes. Med. Care 2019, 57, 353-361. [CrossRef] [PubMed]

16. Sfandyarifard, E.; Tzortzopoulos, P. Supporting Value Generation in Children's Hospital Design through Participatory Approaches. In Proceedings of the 19th Annual Conference of the International Group for Lean Construction, Lima, Peru, $13-15$ July 2011.

17. Tzortzopoulos, P.; Codinhoto, R.; Kagioglou, M.; Rooke, J.A.; Koskela, L.J. The gaps between healthcare service and building design: A state of the art review. Ambiente Construido 2009, 9, 47-55. 
18. Caixeta, M.C.B.F.; Fabricio, M.M. Physical-digital model for co-design in healthcare buildings. J. Build. Eng. 2020, $34,101900$. [CrossRef]

19. Grunden, N.; Hagood, C. Lean-Led Hospital Design: Creating the Efficient Hospital of the Future; CRC Press: Boca Raton, FL, USA, 2012.

20. Abdallah, A.A. Healthcare Engineering: A Lean Management Approach. J. Health Eng. 2020, 2020, 8875902. [CrossRef]

21. Larsen, A.S.A.; Karlsen, A.T.; Andersen, B.; Olsson, N.O. Exploring collaboration in hospital projects' front-end phase. Int. J. Proj. Manag. 2021, 39, 557-569. [CrossRef]

22. Tzortzopoulos, P.; Cooper, R. Design management from a contractor's perspective: The need for clarity. Archit. Eng. Des. Manag. 2007, 3, 17-28. [CrossRef]

23. Kamara, J.; Anumba, C.J.; Evbuomwan, N.F. Capturing Client Requirements in Construction Projects; Thomas Telford: London, UK, 2002.

24. Ryd, N. Facilitating construction briefing-From the client's perspective. Nord. J. Surv. Real Estate Res. 2004, 1, 86-101.

25. Jensen, P.A. Inclusive Briefing and User Involvement: Case Study of a Media Centre in Denmark. Arch. Eng. Des. Manag. 2011, 7, 38-49. [CrossRef]

26. Forgues, D. Maximizing outcomes: Connecting construction project results to business programmes. In Proceedings of the 1st ICEC \& IPMA Global Congress on Project Management, Ljubljana, Slovenia, 23-26 April 2006.

27. Blyth, A.; Worthington, J. Managing the Brief for Better Design; Taylor \& Francis: Hoboken, NJ, USA, 2010.

28. Howie, W. Controlling the Client. New Civ. Eng. 1996, 17, 12.

29. Kelly, J.; Hunter, K.; Shen, Q.; Yu, A. Briefing from a facilities management perspective. Facilities 2005, 23, 356-367. [CrossRef]

30. Dikmen, I.; Birgonul, M.T.; Kiziltas, S. Strategic use of quality function deployment (QFD) in the construction industry. Build. Environ. 2005, 40, 245-255. [CrossRef]

31. Pegoraro, C.; Paula, I.C.D. Requirements processing for building design: A systematic review. Production 2017, 27, 1-18. [CrossRef]

32. Winter, M.; Smith, C.; Morris, P.; Cicmil, S. Directions for future research in project management: The main findings of a UK government-funded research network. Int. J. Proj. Manag. 2006, 24, 638-649. [CrossRef]

33. Koskela, L.; Howell, G.; Ballard, G.; Tommelein, I. The foundations of lean construction. In Design and Construction: Building in Value; Routledge: London, UK, 2002; Volume 291, pp. 211-226.

34. Pikas, E.; Koskela, L.; Seppänen, O. Improving Building Design Processes and Design Management Practices: A Case Study. Sustainability 2020, 12, 911. [CrossRef]

35. Tzortzopoulos, P.; Kagioglou, M.; Koskela, L. Lean Construction: Core Concepts and New Frontiers; Routledge: London, UK, 2020.

36. Tzortzopoulos, P.; Codinhoto, R.; Kagioglou, M.; Koskela, L. Design for operational efficiency: Linking building and service design in healthcare environments. In Proceedings of the Health and Care Infrastructure Research and Innovation Centre (HaCIRIC) International Conference 2008, Brighton, UK, 2-3 April 2018.

37. Forgues, D.; Koskela, L.; Lejeune, A. Toward a client-driven requirement management framework for achieving best value for money. In Proceedings of the 25th Inaugural Construction Management and Economics: Past, Present and Future'Conference, Reading, UK, 16-18 July 2007.

38. Perminova-Harikoski, O.; Hellstrom, M. The Warranty Period as a Service and the Evaluation Point of Project Success. Strateg. Change Towards Future Ind. Serv. Bus. 2015, 58, 200-216.

39. Whelton, M. The Development of Purpose in the Project Definition Phase of Construction Projects; Engineering-Civil \& Environmental Engineering, University of California: Berkeley, CA, USA, 2004; Volume 313.

40. Kärnä, S.; Junnonen, J.-M.K. Designers' performance evaluation in construction projects. Eng. Constr. Arch. Manag. 2017, 24, 154-169. [CrossRef]

41. Shenhar, A.J.; Dvir, D. Toward a typological theory of project management. Res. Policy 1996, 25, 607-632. [CrossRef]

42. Norozpour, R.K. Cultural Paradigms of the Citizen in Project Management. Int. J. Manag. Fuzzy Syst. $2015,1,1$.

43. Tzortzopoulos, P.; Cooper, R.; Chan, P.; Kagioglou, M. Clients' activities at the design front-end. Des. Stud. 2006, 27, 657-683. [CrossRef]

44. D'Andreamatteo, A.; Ianni, L.; Lega, F.; Sargiacomo, M. Lean in healthcare: A comprehensive review. Health Policy 2015, 119, 1197-1209. [CrossRef] [PubMed]

45. Cima, R.R.; Brown, M.J.; Hebl, J.R.; Moore, R.; Rogers, J.C.; Kollengode, A.; Amstutz, G.J.; Weisbrod, C.A.; Narr, B.J.; Deschamps, C. Use of Lean and Six Sigma Methodology to Improve Operating Room Efficiency in a High-Volume Tertiary-Care Academic Medical Center. J. Am. Coll. Surg. 2011, 213, 83-92. [CrossRef] [PubMed]

46. Holden, R.J. Lean Thinking in Emergency Departments: A Critical Review. Ann. Emerg. Med. 2010, 57, 265-278. [CrossRef] [PubMed]

47. Fine, B.A.; Golden, B.; Hannam, R.; Morra, D. Leading Lean: A Canadian Healthcare Leader's Guide. Health Q. $2009,12,32-41$. [CrossRef] [PubMed]

48. Dagenais, M. Analyse Exploratoire des Impacts et des Facteurs de Succès de L'implantation de L'approche Lean Dans Deux Centres Hospitaliers Universitaires Québécois; Ecole Polytechnique: Montreal, QC, Canada, 2012.

49. Houle, L.; Bareil, C.; Gosselin, A.; Jobin, M.H. Le déploiement du lean santé au Québec en mode agile. Quest. (S) de Manag. 2015, 10, 45-64. [CrossRef] 
50. Walley, P.; Found, P.; Williams, S. Failure demand: A concept evaluation in UK primary care. Int. J. Health Care Qual. Assur. 2019, 32, 21-33. [CrossRef]

51. Koskela, L. An Exploration towards a Production Theory and its Application to Construction; VTT Technical Research Centre of Finland: Espoo, Finland, 2000.

52. Yin, R. Case Study Research and Applications: Design and Methods; Sage Publications: Southend Oaks, CA, USA, 2017.

53. Martinsuo, M.; Huemann, M. Designing case study research. Int. J. Proj. Manag. 2021, 39, 417-421. [CrossRef]

54. Yin, R. Case Study Research: Design and Methods, 4th ed.; Sage: Thousand Oaks, CA, USA, 2009.

55. Patton, M.Q. Qualitative research and evaluation methods. In Thousand Oaks. Cal; Sage Publications: Southend Oaks, CA, USA, 2002; Volume 4

56. Fuentes, M.; Smyth, H.; Davies, A. Co-creation of value outcomes: A client perspective on service provision in projects. Int. J. Proj. Manag. 2019, 37, 696-715. [CrossRef]

57. Trischler, J.; Pervan, S.J.; Kelly, S.J.; Scott, D.R. The value of codesign: The effect of customer involvement in service design teams. J. Serv. Res. 2018, 21, 75-100. [CrossRef]

58. Chbaly, H. Alignment Factors between Client Needs and Design Solutions during the Project Definition: Case Study of a Canadian Mega-Hospital Using Lean-Led Design; École de Technologie Supérieure: Montréal, QC, USA, 2021.

59. Monkelbaan, J. Governance for the Sustainable Development Goals; Spinger: Singapore, 2019.

60. Landry, S.; Beaulieu, M. Lean, Kata et Système de Gestion au Quotidien: Réflexions, Observations et Récits D'organisations; Éditions JFD: Montréal, QC, Canada, 2016.

61. Hietajärvi, A.-M.; Aaltonen, K. The formation of a collaborative project identity in an infrastructure alliance project. Constr. Manag. Econ. 2017, 36, 1-21. [CrossRef]

62. Kokkonen, A.; Vaagaasar, A.L. Managing collaborative space in multi-partner projects. Constr. Manag. Econ. 2017, 36, 83-95. [CrossRef]

63. Zerjav, V.; Edkins, A.; Davies, A. Project capabilities for operational outcomes in inter-organisational settings: The case of London Heathrow Terminal 2. Int. J. Proj. Manag. 2018, 36, 444-459. [CrossRef]

64. Whelton, M.; Ballard, G. Project definition and wicked problems. In Proceedings of the IGLC, Boston, MA, USA, 6-8 August 2002.

65. Smith, I.; Hicks, C.; McGovern, T. Adapting Lean methods to facilitate stakeholder engagement and co-design in healthcare. BMJ 2020, 368, m35. [CrossRef] [PubMed]

66. Thyssen, M.H.; Emmitt, S.; Bonke, S.; Kirk-Christoffersen, A. Facilitating client value creation in the conceptual design phase of construction projects: A workshop approach. Archit. Eng. Des. Manag. 2010, 6, 18-30. [CrossRef]

67. Matinheikki, J.; Artto, K.; Peltokorpi, A.; Rajala, R. Managing inter-organizational networks for value creation in the front-end of projects. Int. J. Proj. Manag. 2016, 34, 1226-1241. [CrossRef]

68. Luotola, H.; Hellström, M.; Gustafsson, M.; Perminova-Harikoski, O. Embracing uncertainty in value-based selling by means of design thinking. Ind. Mark. Manag. 2017, 65, 59-75. [CrossRef]

69. Eriksson, J.; Glad, W.; Johansson, M. User involvement in Swedish residential building projects: A stakeholder perspective. Neth. J. Hous. Built Environ. 2014, 30, 313-329. [CrossRef]

70. Eriksson, J. Architects and Users in Collaborative Design; Chalmers Tekniska Hogskola: Göteborg, Sweden, 2014.

71. Hannula, O.; Irrmann, O. Played into collaborating: Design games as scaffolding for service co-design project planning. Simul. Gaming 2016, 47, 599-627. [CrossRef]

72. Steen, M.; Manschot, M.; de Koning, N. Benefits of co-design in service design projects. Int. J. Des. 2011, 5, 53-60.

73. Caixeta, M.; Fabricio, M.; Tzortzopoulos, P. User Involvement at the Early Stages of Design: A case study in healthcare. In Proceedings of the International Postgraduate Research Conference, Salford, UK, 14 June 2013.

74. Lee, C.C.; Egbu, C. Capturing client needs in refurbishment projects. In Proceedings of the 21st Annual ARCOM Conference, London, UK, 7-9 September 2005.

75. Latham, M. Constructing the Team. Joint Review of Procurement and Contractual Arrangements in the United Kingdom Construction Industry; HMSO: London, UK, 1994. 